\title{
Mandible Growth of Wistar Rats: Effects of Malnutrition during Lactation in Adulthood Mandibular Size
}

\author{
Hugo Vieira de Melo Degani jr ${ }^{1}$ Monique da Silva Dias Babinski ${ }^{1}$ Cristiane da Fonte Ramos ${ }^{2}$ \\ Viviane Alexandre Nunes Degani ${ }^{3}$ Lucas Alves Sarmento Pires ${ }^{3}$ Marcio Antonio Babinski ${ }^{3}$
}

\author{
${ }^{1}$ Department of Medical Sciences, Universiddade Federal Fluminense, \\ Niterói, RJ, Brazil \\ 2 Biomedical Center, Department of Anatomy, Universidade do Estado \\ do Rio de Janeiro, Rio de Janeiro, RJ, Brazil \\ 3 Experimental Morphology and Morphometry Unit, Department of \\ Morphology, Universidade Federal Fluminense, Niterói, RJ, Brazil
}

\begin{abstract}
Address for correspondence Marcio Antonio Babinski, PhD, Unidade de Morfometria e Morfologia Experimental, Departamento de Morfologia, Instituto Biomédico, Universidade Federal Fluminense (UFF) Rua Ernani Mello, 101, São Domingos CEP 24.210-150, Niterói, RJ, Brazil (e-mail: mababinski@gmail.com).
\end{abstract}

J Morphol Sci 2018;35:246-250.

\begin{abstract}
Keywords

- lactation

- malnutrition

- mandible

- growth and development

- wistar rats

Introduction Malnutrition is a world health issue; thus, it is imperative to know its effects during lactation. The aim of this study was to evaluate the effects of maternal protein restriction during lactation on the horizontal and vertical bone growth of the mandible, according to predetermined parameters.

Material and Methods At parturition, Wistar rat dams were randomly assigned to the following groups: (1) control, which had free access to a standard laboratory diet containing $23 \%$ of protein; (2) protein energy-restricted, which had free access to an isoenergetic, protein-restricted diet containing $8 \%$ of protein; and (3) energy-restricted group, which received limited access to commercial diet containing $23 \%$ of protein. After 21 days, all pups received free access to a standard laboratory diet containing 23\% of protein until their adulthood. Afterwards, the animals were euthanized under thiopental anesthesia and their mandibles were excised. The dimensions of the excised pup mandibles were measured directly with a digital caliper.

Results The protein-restricted and the energy-restricted groups presented minor adulthood mandibular length in all parameters analyzed.

Conclusion Our results provide original information regarding the mandibular growth and indicate that the maternal nutritional state during lactation can affect the development of mandibular growth. Moreover, our results indicated that the growth dysfunction could not be restored after normalization of the diet.
\end{abstract}

\section{Introduction}

Some investigators have shown that the nutritional status of the mother during gestation and lactation is essential for normal growth and development, both in human and in experimental animals. ${ }^{1,2}$

Previous studies have shown that maternal undernutrition during lactation can cause alterations in breast milk composition, ${ }^{2}$ and serum hormone concentrations, ${ }^{3}$ which can lead to a reduction in body weight. ${ }^{2,3}$

Rats are used as a model for studying human skeletal system and major bone diseases and are considered as a good model for nutritional research., ${ }^{2,4-10}$

Nonetheless, few studies have focused on mandibular growth, especially regarding its relation to nutritional status 4,8 received

July 2, 2017

accepted

November 17, 2017
DOI https://doi.org/

10.1055/s-0038-1676542.

ISSN 2177-0298.
Copyright $\odot 2018$ by Thieme Revinter

Publicações Ltda, Rio de Janeiro, Brazil
License terms

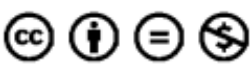


Developmental mandibular abnormalities, both in the horizontal and in the vertical directions, are the most common components of malocclusion. ${ }^{11}$

We consider that this is an important aspect in the field of mandibular development research, as procedures involving this region are emerging and becoming more complex. Also, the study of protein malnutrition effects on mandible is worthwhile, considering the prevalence of this condition in patients, especially in developing countries. ${ }^{1,12,13}$

Thus, the objective of this study was to evaluate the effects of maternal protein restriction during lactation on the horizontal and vertical bone growth of the mandible of the pups in adulthood.

\section{Material and Methods}

\section{Animal Care}

The handling of the animals was approved (CEUA/ 036/2010) by the Animal Care and Use Committee of Universidade do Estado do Rio de Janeiro, which based their analysis on the Guide for the Care and Use of Laboratory Animals. ${ }^{14}$ This study was conducted from April 1, 2010 to June 1, 2012.

\section{Experimental Model}

Six virgin female Wistar rats (3-month-old) were kept in a room with controlled temperature $\left(25 \pm 1{ }^{\circ} \mathrm{C}\right)$ and with artificial dark-light cycle (lights on from 07:00 hours to 19:00 hours) all throughout the experiment and were caged with three male rats. After mating, each female rat was placed in an individual cage with free access to water and food until delivery.

The pregnant Wistar rats were randomly separated at delivery into three groups (two dams per group): group 1 control (C) had free access to water and a standard laboratory diet (in grams per $100 \mathrm{~g}$ ) containing $23 \%$ of protein, $68 \%$ of carbohydrate, $5 \%$ of lipids, $4 \%$ of salts and $0.4 \%$ of vitamins, 4070.4 total energy $(\mathrm{kJ} / \mathrm{kg})$; group 2 - protein energy restricted (PER) had free access to water and to an isoenergetic, protein-restricted diet containing $8 \%$ of protein; and group 3 - energy-restricted (ER) received free access to water and limited access to commercial diet containing $23 \%$ of protein, which corresponded to the same amount ingested in the previous day by rats in group PER. The number of pups used was 6 for each female rat, which totaled 12 per group.

The PER group consumed $60 \%$ of the amount consumed by the control group, in spite of having free access to water and laboratory food. Therefore, the amount of food consumed in both ER and PER groups was almost the same. The low-protein diet was prepared in our laboratory, and vitamin and mineral mixtures were formulated to meet the American Institute of Nutrition AIN-93G recommendation for rodent diets. ${ }^{16}$ The compositions of both diets are depicted in - Table 1 .

To evaluate the nutritional state, the food consumption and body weight were monitored throughout the experiment. Within 24 hours of birth, excess pups were removed, so that only six female pups were kept per dam, as it has been shown that this procedure maximizes lactation performance. $^{14}$
Table 1 Diet composition

\begin{tabular}{|l|l|l|}
\hline Ingredients $\mathbf{( g / k g )}^{\dagger}$ & Control $^{\ddagger}$ & PER $^{\S}$ \\
\hline Total protein $^{\dagger}$ & 23.0 & 8.0 \\
\hline Corn starch & 676.0 & 826.0 \\
\hline Soybean oil & 50.0 & 50.0 \\
\hline Vitamin mixture & 4.0 & 4.0 \\
\hline Mineral mixture & 40.0 & 40.0 \\
\hline $\begin{array}{l}\text { Macronutrient } \\
\text { composition (\%) }\end{array}$ & Control $\ddagger$ & PER§ \\
\hline Protein & 23.0 & 8.0 \\
\hline Carbohydrate & 66.0 & 81.0 \\
\hline Fat & 11.0 & 11.0 \\
\hline Total energy (kcal) & 4070.4 & 4070.4 \\
\hline
\end{tabular}

Abbreviation: PER, protein energy restricted.

†Principal protein resources were soybean wheat, steak, fish and amino acids.

†Standard diet for rats (Nuvilab-Nuvital, Curitiba, Paraná, Brazil).

§The PER diet was prepared in the laboratory at Universidade Federal do Rio de Janeiro by replacing part of the protein content of the control diet with cornstarch. The amount of the latter was calculated to replace the same energy content of the control diet. Vitamin and mineral mixtures were formulated to meet the American Institute of Nutrition AIN-93G recommendation for rodent diets (Reeves et al., 1993). ${ }^{16}$

The maternal malnutrition during lactation was started at birth, which was defined as day 0 of lactation and was ended at weaning (21-days-old). After weaning, 12 female pups of the same treatment group were housed in groups of 3 animals per cage (12 pups per group), and given unlimited access to food and water until adulthood (90-days-old); then, the animals were euthanized under thiopental anesthesia $(0.15 \mathrm{~mL}$ per $100 \mathrm{~g}$ of body weight) and the left ventricle was perfused with buffered saline followed by formalin solution.

The mandibles were excised after perfusion, and they were dissected and stored in formalin solution (10\%).

\section{Morphometric Parameters}

The horizontal and vertical bone growth of 36 mandibles (12 per group) was measured as defined in -Table 2. The parameters are also illustrated in -Figs. $\mathbf{1}$ and $\mathbf{2}$. All measurements in millimeters $(\mathrm{mm})$ were made to the nearest $0.01 \mathrm{~mm}$ using a Mitutoyo digital caliper (Mitutoyo Corp., Kawasaki, Kanagawa, Japan). Both sides of the mandibles were measured.

\section{Statistical Analysis}

The data are reported as mean \pm standard deviation (SD). The statistical significance of the experimental observations was determined using one-way analysis of variance (ANOVA) followed by the posttest of Newman-Keuls to compare the three experimental groups. The level of significance was set at $p \leq 0.05$. A comparison between sides was performed with the Student $t$-test $(p<0.05)$ and was considered statistically significant. The statistical analysis was performed using the GraphPad Prism 5 statistical software (GraphPad, San Diego, CA, USA). 
Table 2 Parameters used in the morphometric analysis

\begin{tabular}{|l|l|}
\hline Parameter & Definition \\
\hline Length measures & $\begin{array}{l}\text { Incisal edge of the lower central incisor tooth - most posterior point of the posterior border of the } \\
\text { mandibular angle }\end{array}$ \\
\hline Length L1 & $\begin{array}{l}\text { Lingual border of the alveolar process of the lower central incisor tooth - most posterior point of the } \\
\text { posterior border of the mandibular angle }\end{array}$ \\
\hline Length L3 & $\begin{array}{l}\text { Incisal edge of the lower central incisor - anterosuperior junction of mandibular body with the mandibular } \\
\text { ramus }\end{array}$ \\
\hline Length L4 & $\begin{array}{l}\text { Lingual border of the alveolar process of the lower central incisor - anterosuperior junction of mandibular } \\
\text { body with the mandibular ramus }\end{array}$ \\
\hline Height measures & \multicolumn{2}{|l|}{} \\
\hline Height H1 & the alveolar process of the first inferior molar tooth (perpendicular to the occlusal plane) \\
\hline Height H2 & Lowest point of the sigmoid notch - Notch antagonist \\
\hline Height H3 & Anterosuperior junction of the mandibular body with the mandibular ramus - Notch antagonist \\
\hline
\end{tabular}

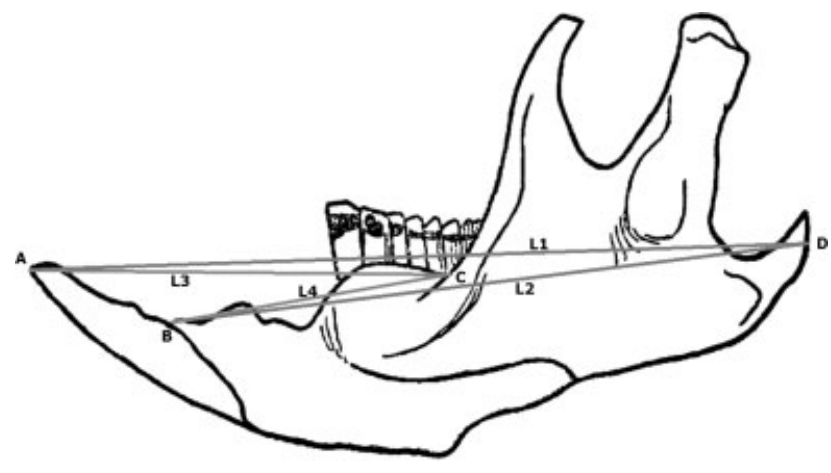

Fig. 1 Rat mandible showing the measurements (length) used in the morphometric analysis. Definitions of acronyms ( $\mathrm{L} 1=$ length 1 , $\mathrm{L} 2=$ length $2, \mathrm{~L} 3=$ length $3, \mathrm{~L} 4=$ length 4 ) are given in $\mathbf{-}$ Table $\mathbf{2}$. Lateral view.

\section{Results}

The mandibular width and height results are shown in -Table 3. These values showed significant differences when analyzing the mandibular body in both experimental groups compared with control. There were no differences

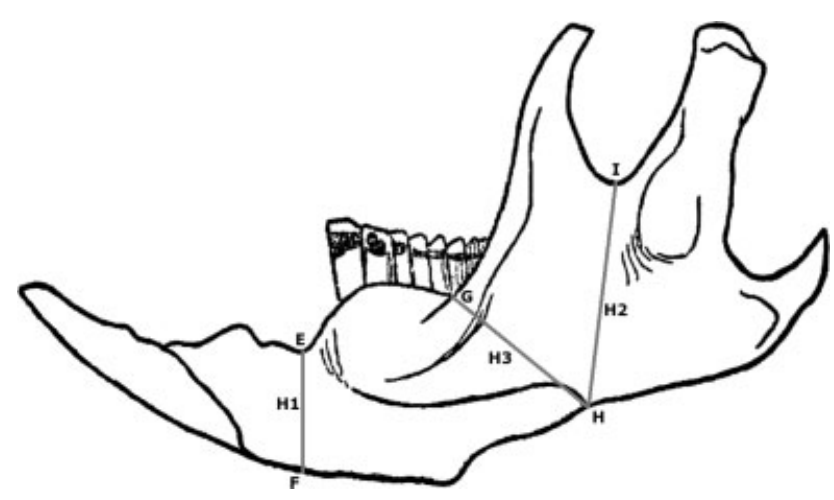

Fig. 2 Rat mandible showing the measurements (height) used in the morphometric analysis. Definitions of acronyms ( $\mathrm{H} 1=$ height 1 , $\mathrm{H} 2=$ height $2, \mathrm{H} 3$ = height 3 ) are given in - Table 2. Lateral view. between the left and right measurements of the mandibles ( $p>0.05)$.

The evaluation of the total length of the mandible showed no significant differences, even on the ramus height, thus suggesting a developmental impairment of the mandibular body.

\section{Discussion}

The strengths of this study may be appreciated in its experimental design, the longitudinal nature of data collection, easy comparison to existing studies ${ }^{5,10}$ using identical animal husbandry protocols, ${ }^{4,10}$ and simultaneous contrast of targeted and catch-up growth.

The craniofacial skeleton is one portion of the body that is critically affected by malnutrition. ${ }^{5,6,9,17}$ The skull is not a single developing unit, but rather has two distinct regions, the viscerocranium and the neurocranium. ${ }^{6,18}$ The viscerocranium is used during the feeding and breathing mechanisms, and its growth is continuously subject to muscular loading, whereas the neurocranium houses the brain, and its growth is influenced primarily by brain expansion. ${ }^{18-20}$

Several studies have examined the effect of nutritional deficiencies on bone growth during gestation, ${ }^{9}$ lactation, ${ }^{6}$ gestation and lactation, ${ }^{19}$ and the post weaning period. ${ }^{21}$ Different forms of retarded cranial growth have been reported, depending on the type of malnutrition and/or its intensity, as well as the period in which the stress was applied. Additionally, the growth of the craniofacial components in rats may be influenced by sex, breed or strain, and nutritional status. ${ }^{9,21}$ In the present study, we used same parameters of our previous study. ${ }^{5}$

Mandible underdevelopment was evident in weaned rats whose mothers were fed PER or ER diets during lactation. In our study, we observed that there was a failed catch-up growth by realimentation until adulthood (90-day-old). We also observed that abnormalities during the lactation period (21-day-old) remained until adulthood. 
Table 3 Morphometric analysis of mandible growth in rat pups at 90 Days

\begin{tabular}{|l|l|l|l|l|}
\hline Parameters & Control group & ER group & PER group & $P$-value \\
\hline Length 1 & $30.78 \pm 0.25$ & $28.35 \pm 3.22$ & $28.05 \pm 2.15$ & 0.09 \\
\hline Length 2 & $24.87 \pm 0.47$ & $23.21 \pm 2.15$ & $22.91 \pm 1.60$ & 0.17 \\
\hline Length 3 & $15.69 \pm 0.55$ & $14.41 \pm 1.50$ & $14.25 \pm 0.88$ & 0.04 \\
\hline Length 4 & $11.02 \pm 0.32$ & $10.09 \pm 0.94$ & $9.70 \pm 0.74$ & 0.02 \\
\hline Height 1 & $4.34 \pm 0.12$ & $3.49 \pm 0.37$ & $3.50 \pm 0.38$ & 0.005 \\
\hline Height 2 & $9.54 \pm 0.46$ & $9.05 \pm 1.18$ & $8.77 \pm 0.60$ & 0.17 \\
\hline Height 3 & $6.30 \pm 0.49$ & $5.53 \pm 0.11$ & $5.37 \pm 0.17$ & 0.002 \\
\hline
\end{tabular}

Abbreviations: ER, energy restricted; PER, protein energy restricted.

Results are shown as mean \pm standard deviation.

The literature on catch-up growth presents a confusing mosaic of results. Several published reports document failed catch-up growth, ${ }^{21,22}$ even in malnourished rats (HERRING, 1993). ${ }^{17}$ There is an equally massive literature documenting successful catch-up growth, ${ }^{23,24}$ including cases of growth restriction that occurred prenatally ${ }^{23}$ [24]. Because growth dynamics are multifaceted, methodological differences among studies prevent straightforward comparisons among these results. Recent reviews outline many of the variables affecting catch-up growth, including length of growth restriction, type of growth restriction, and ontogenetic timing. 25,26

Abnormalities in mandibular development, both vertically and horizontally, are the most common components of malocclusion. Dental skeleton changes, when ranging in intensity from moderate to severe, cause functional (impaired speech, breathing and chewing) and aesthetics problems to patients. ${ }^{27}$ These skeletal malocclusions are difficult to treat, and commonly require correction by means of combined orthosurgical treatments. ${ }^{4}$

To date, according to the literature, no studies regarding morphometric aspects were found; thus, no comparisons could be made with our study, in which we observed that malnutrition during the period of lactation substantially affected the length and height development of the mandibular body, even using a normal and balanced diet after weaning until the end of the 90-days experiment.

Comparing patients with normal occlusion, with class II dental malocclusion, mandibular length was a minor factor. ${ }^{28}$ Patients with class II malocclusion exhibit abnormalities in mandibular development, both vertically and horizontally, as the skull grows mainly due to the growth of the skull base, the condyle and mandible's body. 27,29

In this study, the total length of the mandible and the height of its ramus have been significantly affected. We highlight that the role of intercuspal occlusal control of craniofacial morphogenesis $^{25}$ and stomatognathic functions are influenced by the position of the mandible. Currently, one cannot see occlusion as dependent only on the dental contacts. The main consideration should be the interference pattern of bone growth components of the facial skeleton and skull base. ${ }^{30}$ Studies find that $60 \%$ of patients with atypical swallowing also present body-axis disharmonies ${ }^{28}$ and explain that the center of gravity of the head is anterior to the atlanto-occipital articulation, tending to move forward and downward, which would alter the shaft of the body, and its balance is directly affected by the position of the mandible. ${ }^{30}$

According to the statements above, mothers should be more carefully treated, especially in the current culture of fitness and fast weight loss after birth, which are both subliminally published in newspapers and television. Malnutrition during lactation compromised the development of the mandible's body in its normal length and height, even though a normal and balanced diet was administered after weaning. Since malnutrition is a prevalent condition, we may see a generation with postural problems, craniofacial growth problems ${ }^{6}$ and many other derivatives.

\section{Conclusion}

Our results provide original information regarding the mandibular growth and indicate that the maternal nutritional state during lactation can affect the development of the mandible skeleton and that this could not be restored by an improvement of the diet; thus, the catch-up growth was not successful.

Conflicts of Interest

The authors have no conflicts of interest to declare.

\section{Acknowledgments}

This work was supported by grants from the Foundation for Research Support of Rio de Janeiro (FAPERJ, in the Portuguese acronym), Brazil. The authors report no conflicts of interest related to this study.

\section{References}

1 Babinski MSD, Ramos C, Fernandes R, Cardoso G, Babinski MA. Maternal Malnutrition Diet During Lactation Period Leads to Incomplete Catch-Up Growth in Femur of the Pups at Adulthood. Int J Morphol 2016;34(01):71-77

2 Passos M, Ramos C, Moura E. Short and long term effects of malnutrition in rats during lactation on the body weight of offspring. Nutr Res 2000;20(11):1603-1612

3 Teixeira C, Passos M, Ramos C, Dutra S, Moura E. Leptin serum concentration, food intake and body weight in rats whose 
mothers were exposed to malnutrition during lactation. J Nutr Biochem 2002;13(08):493

4 Bozzini CE, Champin GM, Alippi RM, Bozzini C. Biomechanical properties of the mandible, as assessed by bending test, in rats fed a low-quality protein. Arch Oral Biol 2013;58(04): 427-434

5 Degani H Jr, Nunes V, Bezerra R, et al. Maternal food restriction during lactation reduces mandible growth of the female offspring in adulthood: Experimental and morphometric analysis. Int J Morphol 2011;29(02):598-603

6 Fernandes R, Abreu A, Schanaider A, et al. Effects of protein and energy restricted diet during lactation leads to persistent morphological changes on tibia growth in the weaned pups. Int J Morphol 2007;25(03):565-571

7 Fernandes RM, Abreu AV, Silva RB, et al. Maternal malnutrition during lactation reduces skull growth in weaned rat pups: experimental and morphometric investigation. Anat Sci Int 2008;83(03):123-130

8 He T, Kiliaridis S. Effects of masticatory muscle function on craniofacial morphology in growing ferrets (Mustela putorius furo). Eur J Oral Sci 2003;111(06):510-517

9 Miller JP, German RZ. Protein malnutrition affects the growth trajectories of the craniofacial skeleton in rats. J Nutr 1999;129 (11):2061-2069

10 Rodrigues L, Corrêa L, Luz JG. Healing of displaced condylar process fracture in rats submitted to protein undernutrition. J Craniomaxillofac Surg 2011;39(01):73-78

11 Abed GS, Buschang PH, Taylor R, Hinton RJ. Maturational and functional related differences in rat craniofacial growth. Arch Oral Biol 2007;52(11):1018-1025

12 Correia MI, Campos AC; ELAN Cooperative Study. Prevalence of hospital malnutrition in Latin America: the multicenter ELAN study. Nutrition 2003;19(10):823-825

13 de Onís M, Monteiro C, Akré J, Glugston G. The worldwide magnitude of protein-energy malnutrition: an overview from the WHO Global Database on Child Growth. Bull World Health Organ 1993;71(06):703-712

14 Bayne K; American Physiological Society. Revised guide for the care and use of laboratory animals available. Physiologist 1996;39 (04):199-208-211

15 Reeves PG, Nielsen FH, Fahey GC Jr. AIN-93 purified diets for laboratory rodents: final report of the American Institute of)

16 Fischbeck KL, Rasmussen KM. Effect of repeated reproductive cycles on maternal nutritional status, lactational performance and litter growth in ad libitum-fed and chronically foodrestricted rats. J Nutr 1987;117(11):1967-1975

17 Herring S. Formation of the vertebrate face: Epigenetic and functional influences. Am Zool 1993;33:472-483

18 Pires LAS, Teixeira AR, Leite TFO, Babinski MA, Chagas CAA. Morphometric aspects of the foramen magnum and the orbit in Brazilian dry skulls. Int J Med Res Health Sci 2016;5(04):34-42

19 Pucciarelli HM. Growth of the functional components of the rat skull and its alterations by nutritional effects. A multivariate analysis. Am J Phys Anthropol 1981;56(01):33-41

20 Toews J, Lee M. Permanent skeletal growth retardation in the progeny of rats malnourished during pregnancy and lactation. Nutr Nef Int 1975;11(03):213-222

21 Houdijk ME, Engelbregt MT, Popp-Snijders C, Delemarre van der Waal HA. Long-term effects of early postnatal food restriction on growth hormone secretion in rats. JPEN J Parenter Enteral Nutr 2003;27(04):260-267

22 Oreffo RO, Lashbrooke B, Roach HI, Clarke NM, Cooper C. Maternal protein deficiency affects mesenchymal stem cell activity in the developing offspring. Bone 2003;33(01):100-107

23 Boyer PM, Compagnucci GE, Olivera MI, et al. Bone status in an animal model of chronic sub-optimal nutrition: a morphometric, densitometric and mechanical study. Br J Nutr 2005;93(05): 663-669

24 Jones DC, Bernstein M, German RZ. Catch-up and targeted growth following variable duration protein restriction: effects on bone and body mass. J Morphol 2011;272(04):485-496

25 Andersen HJ, Oksbjerg N, Young JF, Therkildsen M. Feeding and meat quality - a future approach. Meat Sci 2005;70(03): 543-554

26 Cesani MF, Orden B, Zucchi M, Muñe MC, Oyhenart EE, Pucciarelli HM. Effect of undernutrition on the cranial growth of the rat. An intergenerational study. Cells Tissues Organs 2003;174(03): 129-135

27 McNamara JA Jr. Components of class II malocclusion in children 8-10 years of age. Angle Orthod 1981;51(03):177-202

28 Kapoor S, Kapoor DN, Jaiswal JN. Cephalometric evaluation of Class II malocclusions in transitional dentition. J Indian Soc Pedod Prev Dent 2001;19(04):127-133

29 Pucciarelli HM, Oyhenart EE. Influence of food restriction during gestation on craniofacial growth of the weanling rat. Acta Anat (Basel) 1987;129(03):182-187

30 Ferreira F. Ortodontia - Diagnóstico e Planejamento Clínico. São Paulo: Artes Médicas; 1998 